Brit. F. vener. Dis. (1972) 48, 525

\title{
Metronidazole in the single-dose treatment of trichomoniasis in men and women
}

\author{
R. S. MORTON \\ Royal Infirmary, Sheffield
}

In a controlled trial of a single $2 \mathrm{~g}$. dose of metronidazole (Flagyl), Csonka (1971) found a cure rate of 82 per cent. (29 of 36 patients). This compared with a 94 per cent. cure rate (46 of 49 patients) in those treated with $200 \mathrm{mg}$. three times a day for 7 days. Woodcock (1972), in a similar trial, found recurrence rates of 15 and 13.7 per cent. respectively in those treated with the new regime and in controls. He commented that whereas a single $2 \mathrm{~g}$. dose of metronidazole appeared to offer satisfactory therapy in women, it did not follow that it would be satisfactory for their consorts.

The present study was designed to test the efficacy of the single $2 \mathrm{~g}$. dosage regime in both females and males.

\section{Study of females}

\section{METHODS}

138 consecutive female cases of vaginal trichomoniasis were seen between April and November, 1971. Diagnosis was made by dark-ground microscopy of the vaginal contents. Each patient was treated with a single dose of 2g. metronidazole (five tablets each of $400 \mathrm{mg}$.) given under supervision in the clinic. Follow-up tests, also by dark-ground microscopy of the vaginal contents, were planned to take place at weekly intervals for 3 weeks after treatment.

Received for publication June 21, 1972

Paper read at the Jubliee Meeting of the M.S.S.V.D. at Glasgow on June 10, 1972

\section{FINDINGS}

The average age of the 138 female patients was $22 \cdot 2$ years (range 15 to 47 ). 87 were single.

Table I shows that 118 women had at least one followup examination and that 75 completed three tests (or more) as planned.

Recurrence was detected in 21 ( 17.8 per cent.) of the 118 followed.

TABLE I Follow-up of 138 female patients treated with $2 \mathrm{~g}$. metronidazole for trichomoniasis

\begin{tabular}{|c|c|}
\hline No. of follow-up tests & No. of patients \\
\hline None & 20 \\
\hline One & 24 \\
\hline Two & 19 \\
\hline Three or more & 75 \\
\hline
\end{tabular}

Table II attempts to analyse the recurrences in terms of test order, interval between treatment and testing, and sex history after treatment. The findings suggest that recurrences in this series of patients were about equally divided between failure and re-infection.

\section{SIDE-EFFECTS}

One woman had nausea and vomited a little. Her followup tests proved satisfactory without further treatment being given.

TABLE II Recurrences of $\mathrm{T}$. vaginalis in women in terms of test order, time, and post-treatment sex history

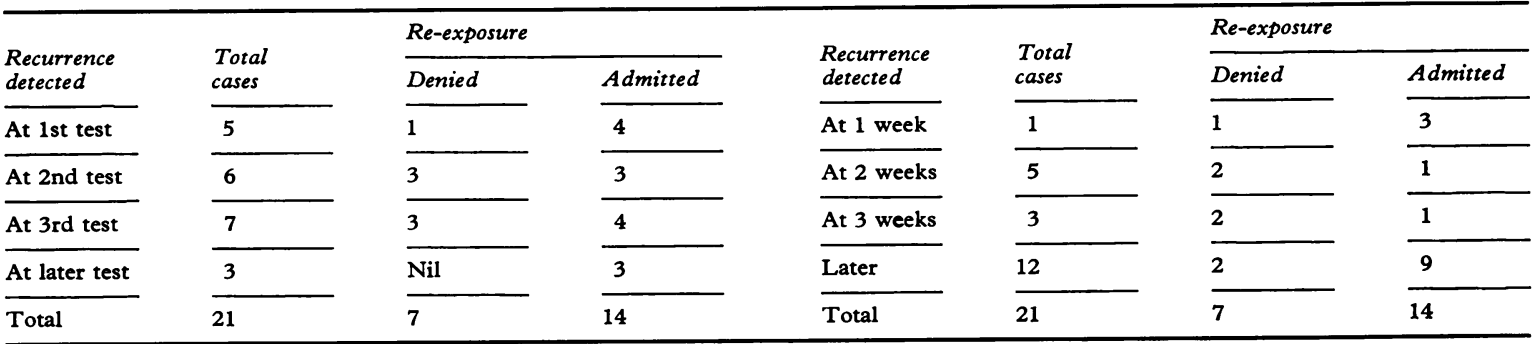




\section{Study of males}

\section{METHODS}

Between April 1971 and January 1972 seventy-six male consorts of patients with vaginal trichomoniasis were investigated. It was planned to examine specimens from the men on three occasions (or less if positive findings were made) by dark-ground microscopy and by culture methods. Specimens were obtained of urethral scrapings and/or centrifuged urine deposit, prostatic secretion and the centrifuged urine deposit after prostatic massage. Culture specimens were sent to the local public health laboratory in Stuart's medium for inoculation of a modified Feinberg-Whittington medium.

Men found harbouring trichomonas vaginalis, together with any others found infested during the study period, were treated with a single $2 \mathrm{~g}$. dose of metronidazole given under supervision in the clinic.

Patients were asked to attend at weekly intervals for three sets of follow-up tests identical with those used for diagnosis.

FINDINGS

Table III shows the number of investigations and the stage at which positive findings were made. Of the 76 consorts examined, ten (13.1 per cent.) gave positive results. Half the positive findings were made at the first examination. All the consorts were asymptomatic.

TABLE III Detection of Trichomonas vaginalis in male consorts of women with trichomoniasis

\begin{tabular}{|c|c|c|}
\hline Series of tests & $\begin{array}{l}\text { No. of consorts of } \\
\text { female patients }\end{array}$ & T. vaginalis found \\
\hline One & 42 & 5 \\
\hline Two & 9 & 3 \\
\hline Three & 25 & 2 \\
\hline Total & 76 & 10 \\
\hline
\end{tabular}

Another six males with trichomoniasis were found during the study period. Two of these men complained of urethral discharge, and the other four had vague genito-urinary symptoms. In five, the positive findings were made at the first examination of urethral discharge or scraping and in the sixth at a second testing; one man also had a positive urethral culture.

Table IV shows the procedure which revealed infestation in the total of sixteen men concerned in this study.

TABLE IV Method of detection of trichomoniasis in 16 males

\begin{tabular}{|c|c|c|}
\hline Dark-ground microscopy of: & Consorts & Others \\
\hline Urethral scrapings & 9 & 5 \\
\hline Prostatc secretion & 1 & Nil \\
\hline Centrifuged first urine & Nil & 1 \\
\hline Post-prostatic massage urine & Nil & Nil \\
\hline Total & 10 & 6 \\
\hline
\end{tabular}

Dark-ground examination of urethral material proved the most productive method. The one man in whom Trichomonas vaginalis was found in the prostate also had a positive prostatic culture result. His four recent consorts all had trichomonal vaginitis.

The average age of the 82 men concerned in this study was 30.7 years (range 17 to 62 ). The average age of the sixteen infested men was $37 \cdot 8$ years (range 24 to 54 ).

Of the total of 82 men, 43 (52 per cent.) were married. Half of the sixteen infested men were married.

Table $\mathrm{V}$ shows the degree of co-operation of patients as judged by attendance for follow-up tests. Ten men completed the planned follow-up.

TABLE V Follow-up of 16 males treated for trichomoniasis

\begin{tabular}{|c|c|}
\hline Series of tests & No. of cases \\
\hline Defaulted & 2 \\
\hline One series & 1 \\
\hline Two series & 3 \\
\hline Three series & 10 \\
\hline Total & 16 \\
\hline
\end{tabular}

As in the diagnostic procedure it was occasionally impossible to obtain urine samples or a prostatic bead, or the patient refused prostatic massage.

The patient with trichomonal prostatitis was amongst those completing three follow-up tests.

No recurrences were detected.

\section{SIDE EFFECTS}

One man had a bout of retching but did not vomit. Another felt momentarily dizzy.

\section{Discussion}

The part of the study concerning females gives a recurrence rate similar to that reported by Csonka (1971) and Woodcock (1972). The true treatment failure rate in the present series cannot be accurately determined. In contrast to the regime of $200 \mathrm{mg}$. metronidazole three times a day for 7 days, the single-dose therapy employed must be seen as giving an increased chance of re-infection during the time taken to investigate the male consort. The attempted analysis of recurrent cases suggests that the cure rate with a single $2 \mathrm{~g}$. dose of metronidazole may be around 90 per cent.

The culture medium gave disappointing results in males although it was found to be satisfactory for females. The reason is unknown.

It is of interest that, in the series of males, both as consorts and as infected patients, the average age is much higher than that of the females and higher than one would expect to find in a group of males with gonorrhoea. 
The series of males treated is small. Nevertheless the satisfactory results obtained by detailed follow-up testing on three occasions in ten of the sixteen suggests that a single $2 \mathrm{~g}$. dosage regime is highly effective in males with trichomoniasis.

The disparity in recurrence rates between females and males suggests the need for an epidemiologically orientated study of male/female partnerships when both partners are found infested, treated simultaneously, and followed-up by direct microscopy and culture testing.

\section{Summary and conclusions}

Of 138 women with vaginal trichomoniasis treated with a single $2 \mathrm{~g}$. dose of metronidazole, 118 were seen for follow-up examination on at least one occasion and 75 had three or more follow-up tests.

There were 21 recurrences (17.8 of those followed).

An attempt to define recurrence in terms of treatment failure and re-infection suggests that the true cure rate for this regime may be around 90 per cent.

Sixteen males with trichomoniasis were also treated with a single $2 \mathrm{~g}$. dose of metronidazole.

Ten of these male patients were detected by detailed investigation of a group of 76 consorts of women with trichomonal vaginitis, and six others were found by routine examination of men presenting with genito-urinary symptoms.

Fourteen of the sixteen men treated had at least one follow-up series of tests and ten had three series of detailed tests by microscopy and culture. No recurrences were detected.

It is concluded that a simple $2 \mathrm{~g}$. treatment schedule with metronidazole is adequate treatment for trichomoniasis in both sexes.
My thanks are due to colleagues who referred the husbands of their patients; to the staff of the Sheffield Public Health Laboratory; and to Mr. Shaw, S.R.N., and members of the clinic staff, whose co-operation in this study is appreciated.

May and Baker supplied the $400 \mathrm{mg}$. tablets of metronidazole (Flagyl).

\section{References}

Csonka, G. W. (1971) Brit. vener. Dis., 47, 456

Woodcock, K. R. (1972) Ibid., 48, 65

Traitement de la trichomonase féminine et masculine par une dose unique de métronidazole SOMMAIRE

138 femmes atteintes de trichomonase vaginale furent traitées par une dose unique de $2 \mathrm{~g}$. de métronidazole; parmi elles, 118 subirent un examen de contrôle au moins une fois, 75 ont été contrôlées trois fois et plus.

Il y eut 21 récidives (17,8 pour cent des cas suivis).

Les recherches faites pour tenter de distinguer parmi ces récidives les échecs thérapeutiques et les réinfections suggèrent que le taux réel de guérison avec le traitement décrit doit être d'environ 90 pour cent.

Seize hommes atteints de trichomonase furent aussi traités avec une dose unique de $2 \mathrm{~g}$. de métronidazole.

Dix de ces hommes avaient été découverts en examinant d'une manière détaillée un groupe de 76 conjoints de femmes ayant une vaginite à trichomonas; les six autres furent trouvés lors d'examens de routine d'hommes présentant des symptômes génito-urinaires.

Quatorze des seize hommes traités ont eu au moins une série de tests de contrôle et dix ont eu trois séries de contrôle complet, par microscopie et culture. Il ne fut noté aucune rechute.

On conclut que le traitement par une dose unique de $2 \mathrm{~g}$. de métronidazole convient pour la trichomonase dans les deux sexes. 